\title{
LA MISERICORDIA EN EL ITINERARIO VOCACIONAL
}

DOI: https://doi.org/10.52039/seminarios.v62i216.148

«Ser de Dios, la misericordia. Carisma sacerdotal». Este es lema del simposio que estamos celebrando y la ponencia marco de este día: «El sacerdote, testigo y ministro de la misericordia».

Las distintas reflexiones y comunicaciones que se nos han expuesto nos han ayudado a tomar conciencia de aquellos rasgos que son propios de los sacerdotes y que han de ser los que un joven seminarista debe asimilar para su futuro comportamiento pastoral en la Iglesia y en la sociedad.

El carisma original del ministerio de los pastores viene afirmado y comprendido hoy desde la categoría de "sacramento». En Pastores dabo vobis esta afirmación viene recogida a lo largo de todo el documento con los términos: transparencia, epifanía, icono.

Por la ordenación nos convertimos en signo personal viviente, que remite y pone de relieve y visibiliza a Cristo, Cabeza y Pastor, y actúa en su nombre en beneficio de la comunidad. Por tanto, no es tan importante lo que hacemos cuanto el hecho de significar sacramentalmente la presencia y la actuación salvífica de Cristo pastor.

Actualmente, seminaristas y sacerdotes se desenvuelven en un haz de relaciones que configuran su estilo de vida. Como nos dice Pastores dabo vobis, la caridad pastoral es el rasgo fundamental y unificador de todos los demás. Gracias al sacramento del Orden, «la vida espiritual del sacerdote queda caracterizada, plasmada y definida por aquellas actitudes y comportamientos que son propios de Jesucristo, Cabeza y Pastor de la Iglesia, y que se compendian en la caridad pastoral» (PDV 21; cf. n. 23).

Hoy por hoy, es el seminario el lugar más propio para iniciar a los candidatos al sacerdocio en las llamadas virtudes sacerdotales. Si el sacerdote es signo sacramental de Cristo pastor (cf. LG 28; PO 12; PDV 21-23), hay rasgos y actitudes que no pueden faltar en la vida de los pastores. De entre todos, el rasgo

* Jesús Rico García es sacerdote operario diocesano. Tras un sexenio en el servicio de Director General de la Hermandad, actualmente es Rector del Aspirantado de los Sacerdotes Operarios, en México. 
básico, primordial y de identificación vital del sacerdote con Cristo es su amor identificativo; esto es, encarna en sí las actitudes, acciones, comportamientos y sentimientos de Cristo.

La misericordia es una modalidad del amor. En los sacerdotes, la misericordia es una cualidad del amor pastoral. Es el rasgo esencial de Cristo pastor. Él se dejó afectar por el sufrimiento, la pobreza, la miseria, el pecado de sus contemporáneos. Se le conmueven las entrañas y «siente compasión de la gente porque andaban como ovejas sin pastor» (Mc 6, 36). Fruto de esta compasión es la triple actividad de Jesús: la enseñanza, la curación de los enfermos y la multiplicación de los panes. Jesús mismo fue ya el primer testigo de la misericordia de Dios, como lo han de ser sus sacerdotes. La identificación con Jesús exige en el presbítero una caridad pastoral «que le empuja a conocer cada vez más las esperanzas, necesidades, problemas, sensibilidad de los destinatarios de su ministerio, los cuales han de ser contemplados en situaciones personales, familiares y sociales concretas» (PDV 70).

Si la misericordia es un rasgo esencial y central, su contrasigno sería un pastor insensible y duro. Los seminaristas como futuros candidatos a ser pastores, han de empezar a vivir estos rasgos en su etapa de formación, ofrecida por el seminario. La relación con Cristo, pastor misericordioso, debe ir creciendo gradual y paulatinamente durante los años de formación.

Bajo la cobertura de este rasgo general reflexionaremos acerca de la misericordia por medio de la cual el presbítero realiza su condición de ser signo sacramental de Cristo pastor y ofreceremos algunas indicaciones para ir implementando ésta en el proceso formativo.

\section{LA MISERICORDIA EN LA FORMACIÓN SACERDOTAL}

Esta cualidad sacerdotal de la misericordia, que el sacerdote ha de vivir y ejercer, ha de situarse como trasfondo de la formación en el seminario, y debe orientar las opciones pedagógicas que se van asumiendo en cada una de las áreas formativas.

Antes que nada el seminarista debe reconocerse como agraciado por la misericordia de Dios. Ha sido llamado gratuitamente y debe vivir su vocación como un regalo que el Señor le ha hecho y como una respuesta agradecida a ese don.

Todas las dimensiones formativas que el seminario ofrece están llamadas a promover la misericordia pues todas están relacionadas entre sí y crecen a la vez, dependiendo interiormente unas de otras.

Los «Planes de Formación Sacerdotal para los Seminarios Mayores», ofrecen tres medios ya clásicos para conseguir los objetivos de cada dimensión y etapa formativa, que sin duda también nos ayudan para ir madurando en la misericordia: el propio proyecto personal de vida que nos permite concretar y 
formular desafíos u objetivos; la mediación de un acompañante (dirección espiritual) que ayudará a ir definiendo el estilo de vida del seminarista; y el proyecto de vida comunitario, como forma más inmediata de practicar la misericordia con los compañeros y formadores, con los que convive a diario el seminarista.

La formación comunitaria tendrá repercusiones importantes en el modo de promover y vivir la misericordia en el tiempo de permanencia en el seminario, dado que influye en la forma determinada de vivir las normas de convivencia, educa a los seminaristas en ir consiguiendo una mayor libertad interior, ayuda a ejercitarse en unas relaciones sanas y de calidad entre los compañeros y responsabilizarse de encargos que le irán haciendo crecer en actitudes de servicio a la comunidad.

Todo lo dicho se enmarca en un proceso gradual, vivido a través del tiempo de su permanencia en el seminario.

\section{Etapa de filosofía': Etapa estructuradora}

Es una etapa en la que el seminarista ha de irse liberando de todas las «esclavitudes» o inconsistencias que le tienen centrado en sí mismo y le incapacitan para una correcta visión de sí mismo y su auténtica realización, además de un seguimiento más auténtico y libre de Jesús. No olvidemos que «no se sigue, porque se deja. Se deja, porque se sigue» (cf. Mt 13, 44-45). Por eso, el conocimiento e identificación con la persona de Jesús será clave en estos años de filosofía. Es importante hacer un planteamiento positivo de esa liberación interior que poco a poco tiene que ir consiguiendo, colocando el amor como objeto de las verdaderas decisiones humanas. «Liberarse para». Si el Señor nos ha liberado es para que nosotros, a imitación suya, nos ofrezcamos como don para los demás.

Hemos de presentar a Jesús como modelo de entrega. Un hombre para los demás. El servicio es uno de los ejes existenciales en su vida. Toda su vida está consagrada a los demás. Para definir su modo de estar entre los hombres y el modo como deberán estar sus discípulos, dice: «El Hijo del hombre no ha venido para que le sirvan, sino para servir» (Mc 10, 44-45). Su solo testimonio constituye la mejor razón para seguirlo y adoptar su modo de vida caracterizado por el servicio.

El camino discipular es un camino de servicio. Conviene por eso estar atentos a las necesidades de los demás. Ellas son mediación clara de la llamada de Dios en la vida del seminarista.

1. Servicios de animación vocacional Sol, Los itinerarios formativos en el seminario diocesano. Directorio para la formación sacerdotal, México 2012, 343-413. De esta obra se pueden sacar una serie de elementos muy útiles para la formación sacerdotal sobre el tema que nos ocupa. 


\section{Etapa de teología²: Etapa configuradora}

El objetivo de esta etapa consiste en que el candidato se configure con Cristo, Buen Pastor, que da la vida en favor del pueblo de Dios.

El icono de esta etapa será Cristo, Buen Pastor, que da su vida por el rebaño. Por un lado, la solemne manifestación de Jesús: Yo soy el buen pastoren Jn 10 , 11-16; por otro lado, la imagen entrañable de Jesús como Buen Pastor, reflejado en las parábolas, deberá ser asimilado en los años de teología.

Ya el título de cada una de estas parábolas nos hace caer en la cuenta de que el amor misericordioso de Dios Padre desborda todos nuestros cálculos y de que contiene un valor universal: El Hijo pródigo (Lc 15); el buen Samaritano (Lc 10, 29-37); el rico Epulón y el pobre Lázaro (Lc 16, 19-30); el siervo sin entrañas (Mt 18, 23-25); el juicio final (Mt 25, 31-46). En estos relatos evangélicos aparecen varias clases de personas (enfermos, pecadores, abandonados...) que reclaman una actitud misericordiosa de Jesús, de orden espiritual o de orden humano.

Finalmente, querría resaltar dos aspectos que considero especialmente relevantes hoy y de necesario tratamiento en la etapa formativa.

El primero sería ayudar a superar el narcisismo tan presente hoy en el mundo juvenil y en nuestra cultura en general en la que se ha «desbordado caudalosamente. El amor impregnado de este narcisismo se ha curvado sobre sí mismo y ha perdido vigor y frescor para abrirse a un amor oblativo a otras personas, comunidades y causas. Quien lo padece es un perfecto mendigo de amor, de aprecio, de elogio, de admiración acrítica. Un mendigo perpetuamente insatisfecho. Siempre considera insuficiente y deficiente el amor que recibe. Un narciso que ha cuajado en su narcisismo no es capaz de amar con amor oblativo, un amor que respeta la libertad de los demás, que renuncia a la tentación de seducir» ${ }^{3}$.

Es necesario ayudar a los seminaristas a crecer en este amor oblativo propio del pastor. Para ello es conveniente que los seminaristas estén cercanos al mundo del dolor, de la soledad, de la pobreza y se sientan concernidos por esa realidad. Esta será una de las terapias efectivas para superar el narcisismo que pueda encerrarlos en sí mismo y dificultarlos la entrega generosa, propia del pastor. Así mismo será necesario que a estas personas las eduquemos a situarse en la comunidad, en la que normalmente buscan provecho personal, esperando tantas veces imposibles, siendo constructores de comunidad y agentes activos de la misma. Pasar de una actitud pasiva y del que todo lo espera de los demás, a una actitud activa y colaboradora. Estas dos líneas de acción sin

2. Servicios de animación vocacional Sol, Itinerarios, 427-431.505-523.

3. J. M. Uriarte, El celibato. Apuntes antropológicos, espirituales y pedagógicos, Santander 2015, 23-25. 
duda que contribuirán a educar al futuro pastor en la oblatividad, característica indispensable en su futuro ejercicio ministerial.

El segundo aspecto a destacar es ¿cómo ayudar a que las propias debilidades sean una escuela para aprender a sintonizar con las debilidades de los demás.

La carta a los Hebreos nos dice que la eficacia del ministerio y del sacerdocio de Cristo están precisamente en la fragilidad: «Pues no tenemos un Sumo sacerdote que no pueda compadecerse de nuestras flaquezas, sino probado en todo igual que nosotros, excepto en el pecado» $(\mathrm{Hb} \mathrm{4,15)}$.

Hoy nos entran en nuestros seminarios personas con muchas heridas sin curar. Es importante que en el proceso formativo les enseñemos a asumir la experiencia de debilidad, de modo que puedan integrar todas sus carencias. En Pastores dabo vobis se nos dice de una manera magistral que el sacerdote «debe acrecentar y profundizar aquella sensibilidad humana que le permite comprender las necesidades y acoger los ruegos, intuir las preguntas no expresadas, compartir las esperanzas y expectativas, las alegrías y los trabajos de la vida ordinaria; ser capaz de encontrar a todos y dialogar con todos. Sobre todo conociendo y compartiendo, es decir, haciendo propia la experiencia del dolor en sus múltiples manifestaciones, desde la indigencia a la enfermedad, de la marginación a la ignorancia, a la soledad, a las pobrezas materiales y morales, el sacerdote enriquece su propia humanidad y la hace más auténtica y transparente en un creciente y apasionado amor al hombre» (PDV 72).

Reconocer nuestras debilidades y los sufrimientos de los demás y hacer de esta experiencia un lugar educativo es trascendental para el futuro pastor y fuente de superación de sus heridas. Lo que se asume es lo que se redime. Esta aceptación del sufrimiento llevará a reforzar la experiencia de gratuidad, de reconocer que hemos sido llamados de un modo gratuito y que lo que somos, lo somos por gracia. Podremos presumir como Pablo de la fuerza de nuestra debilidad, a través de la cual Dios se manifiesta (cf. 1 Cor 4, 7-18). En su debilidad ha de descubrir el seminarista la presencia liberadora y misericordiosa de Dios. Por eso, es bueno que aprenda a enfrentarse y mirar con serenidad, e incluso cariño, sus contrariedades, viendo que no solo no son obstáculo para el encuentro con el Señor, sino posibilidad para su manifestación y mejor acompañar a los que están envueltos en debilidad.

El pastor habrá de ser agente de la misericordia en una cultura donde lo que cuenta es el éxito, la eficacia, el poder, y lo débil es descartado y no tenido en cuenta. Su experiencia de la debilidad, hecha escuela de formación le dará una sensibilidad especial frente a los desechados y excluidos de nuestra sociedad, que son los preferidos del Señor.

El día de mañana el seminarista será «ministro de la reconciliación». Ya desde el seminario deberá celebrar y vivir esta reconciliación. «La gracia sanante del sacramento de la reconciliación es una necesidad y un poderoso auxilio 
cuando el acceso a él es frecuente, sincero y motivado por un deseo de fidelidad mayor. Las heridas psicológicas inscritas en el psiquismo perviven, pero el sacramento nos ayuda a sumirlas pacientemente y aminorar sus efectos $»^{4}$.

\section{EN LA PROMOCIÓN VOCACIONAL}

La misericordia entendida como el servicio a la caridad es una de las mediaciones más característica de la comunidad eclesial. La Iglesia primitiva nos muestra los rasgos de la acogida, la caridad y atención a los necesitados como algo clave en su actuación y fuente de atracción para los no cristianos.

La experiencia del servicio es experiencia de humanidad y misericordia. Esta sin duda puede ser un medio importante en la promoción vocacional y de cara a discernir la propia vocación. En estas experiencias muchos jóvenes han encontrado a Dios y a sí mismos. Las situaciones de necesidad son llamadas; Dios llama desde las necesidades para pedir respuestas concretas (cf. Ex 3, 1-10.17; 6, 2-13; 17, 1-15; Nm 12; 14).

Hoy se habla de la importancia de promover "experiencias fundantes». Una de ellas es colocar a nuestros jóvenes en contextos de marginación, de opción por la pobreza. «Vivir en contacto, experimentar y adoptar un tipo de vida claramente diferente a los valores dominantes en la sociedad, especialmente en el campo de la relación interpersonal, no mercantilizada, no explotadora, sino fraterna y en el campo de uso y de sentido de la riqueza, de los bienes, mediante un testimonio de vivencia de la pobreza evangélica sin paliativos, del compartir hasta los mismos bienes económicos. Y como parte de esta experiencia participar en gestos transformadores de la realidad, en gestos de lucha por la liberación de los pobres con todos los riesgos que ello supone y la felicidad honda, aunque sea martirial, que ello comporta» ${ }^{6}$.

tra de esas experiencias fundantes, según el autor citado, es la experiencia de comunitariedad. Aproximar al joven a experiencias de auténtica vida fraterna, el contacto con comunidades, que podríamos llamar alternativas. Donde se haga realidad la valoración y respeto del otro, tratándole como prójimo y hermano, donde se comparte lo que se es y tiene.

Así mismo el testimonio de vidas entregadas y misericordiosas será uno de las mediaciones más importantes en la pastoral de las vocaciones, especialmente con los jóvenes. Antes que con discursos y palabras la pastoral vocacional llega por contagio. Como ya decía el gran papa Pablo VI: «el hombre contemporáneo prefiere a los testigos antes que a los maestros» (EN 41). Por eso, «el método fundamental de la nueva evangelización han de ser praxis

4. J. M. Uriarte, El celibato, 181.

5. L. Rubio Morán, Nuevas vocaciones para un mundo nuevo, Salamanca 2002, 64-70.

6. Ibid., 60. 
personales y también comunitarias, carismático-institucionales, en las que se haga verdad patente y visible 'la benevolencia y el humanitarismo de nuestro Dios' (Tit 3, 4)» ${ }^{7}$.

Evidentemente los testimonios más cercanos son los propios formadores, que no deberían olvidar el adagio latino: «verba docent, exempla trahunt». Las palabras enseñan, los ejemplos atraen. Un ejemplo lo tenemos en san Juan María Vianney, que el papa Benedicto XVI, con motivo del Año Sacerdotal, nos lo propuso a los sacerdotes como ejemplo. «Los sacerdotes podemos aprender del santo Cura de Ars no sólo una confianza infinita en el sacramento de la penitencia, que nos impulse a ponerlo en el centro de nuestras preocupaciones pastorales, sino también el método del 'diálogo de salvación' que en él se debe entablar. El Cura de Ars se comportaba de manera diferente con cada penitente. Quien se acercaba a su confesonario con una necesidad profunda y humilde del perdón de Dios, encontraba en él palabras de ánimo para sumergirse en el 'torrente de la divina misericordia' que arrastra todo con su fuerza» ${ }^{8}$.

En aquel tiempo logró transformar el corazón de muchas personas, porque les hizo sentir el amor misericordioso de Dios. Por eso, es necesario que la Iglesia (los pastores), como nos recuerda Juan Pablo II en Dives in misericordia no sólo acoja la misericordia sino que la transmita: «Es preciso que la Iglesia de nuestro tiempo adquiera conciencia más honda y concreta de la necesidad de dar testimonio de la misericordia de Dios en toda su misión» (DM 12).

Como conclusión a esta información, termino con un texto de Pastores dabo vobis que resume e ilustra todo lo dicho: "La promesa de Dios asegura a la Iglesia no unos pastores cualesquiera, sino unos pastores según su corazón. El corazón de Dios se ha revelado plenamente a nosotros en el Corazón de Cristo buen Pastor. Y el Corazón de Cristo sigue hoy teniendo compasión de las muchedumbres y dándoles el pan de la verdad, del amor y de la vida (cf. Mc 6, 30s), y desea palpitar en otros corazones -los de los sacerdotes-; 'Dadles vosotros de comer' (Mc 6, 37). La gente necesita salir del anonimato y del miedo; ser conocida y llamada por su nombre; caminar segura por los caminos de la vida; ser encontrada si se pierde; ser amada; recibir la salvación como don supremo del amor de Dios; precisamente esto es lo que hace Jesús, el buen Pastor; Él y sus presbíteros con Él» (PDV 82).

7. L. Rubio, Nuevas vocaciones, 70

8. Benedicto XVI, Carta para la convocación de un Año Sacerdotal con ocasión del 150 aniversario del dies natalis de Juan María Vianney (16 de junio de 2009). 